\title{
The Common Misconceptions about Sign Language
}

\section{Khunaw Sulaiman Pirot}

Department of English, College of Languages, University of Salahaddin, Erbil, Kurdistan Region, Iraq.

E-mail: khunaw.sulaiman@uor.edu.krd

\section{Wirya Izzaddin Ali}

Department of English, College of Languages, University of Salahaddin, Erbil, Kurdistan Region, Iraq.

E-mail: wryaizzadin@yahoo.com

\section{Abstract}

This paper entitled 'The Common Misconceptions about Sign Language' is concerned with the most common misconceptions about sign language. It also deals with sign language and its relation with the spoken language. Sign language, primarily used by deaf people, is a fully-developed human language that does not use sounds for communication, but it is a visual-gestural system that uses hands, body and facial gestures. One of the misconceptions is that all sign languages are the same in the worldwide. Such assumptions cause problems. Accordingly, some questions have been raised: first, is sign language universal? Second, is sign language based on spoken language? And third, is sign language invented by hearing people?

The aim of the paper is to have a deeper understanding about sign language. It also demonstrates the similarities and differences between the two different modalities: sign language and spoken language. The paper is based on some hypothesis. One of the hypotheses is that sign languages are pantomimes and gestures. It also hypothesizes that the process of language acquisition in sign language for deaf people is different from the language acquisition in spoken language for hearing people.

To answer the questions raised, the qualitative approach is adopted. The procedure is to collect data about the subject from books and articles and then analyze the data to obtain the aim of the study. One of the conclusions is that sign language is not universal. It is recommended that more work can be carried out on the differences between either American Sign Language (ASL) or British Sign Language (BSL) with reference to zmânî âmâžaî kurdî (ZAK) Kurdish Sign Language) at all linguistic levels.

Keywords: Sign Language, Visual-Gestural System, Deaf People, Modalities. 
Key of Abbreviations

\begin{tabular}{|l|c|}
\hline ASL & American Sign Language \\
\hline Auslan & Australian Sign Language \\
\hline BSL & British Sign Language \\
\hline Codas & Children of Deaf Adults \\
\hline DSL & Danish Sign Language \\
\hline DGS & German Sign Language-Deutsche Gebärdensprache \\
\hline GSL & Hamburg Notation System \\
\hline HamNoSys & Israeli Sign Language \\
\hline ISL & First Language Acquisition \\
\hline L1 & Langue des Signes Francaise \\
\hline LIS & Manually Coded English \\
\hline LSF & Manual Sign Codes \\
\hline MCE & Nicaragua Sign Language \\
\hline MSCs & Signed English \\
\hline NSL & Signed Exact English \\
\hline SE & Sign Language(s) \\
\hline SEE &
\end{tabular}

\section{List of Figures}

\begin{tabular}{|c|c|c|}
\hline Figure & Title & Page \\
\hline Figure 1 & Four signs in Auslan & 5 \\
\hline Figure 2 & Sign for WOMAN for two unrelated sign languages & 9 \\
\hline Figure 3 & ASL and BSL manual alphabets and numbers & $11-12$ \\
\hline Figure 4 & Correspondences between human legs and index and middle finger & 14 \\
\hline Figure 5 & Iconic gesture accompanying peels of the banana & 14 \\
\hline Figure 6 & The ASL sign BANANA & 15 \\
\hline Figure 7 & $\begin{array}{c}\text { The correspondence between (a) a prototypical image of a tree and } \\
\end{array}$ & 15 \\
\hline
\end{tabular}

\section{Notational Conventions for SLs}

\begin{tabular}{|c|c|}
\hline SIGN & Lexical sign \\
\hline -s-i-g-n- & Fingerspelled word \\
\hline
\end{tabular}

\section{List of Tables}

\begin{tabular}{|l|c|c|}
\hline Table & Title & page \\
\hline Table 1 & Non-manual signs & 6 \\
\hline
\end{tabular}




\section{Introduction}

The majority of people believe that speech is the only medium of language. On the contrary, speech is not the only medium. Within the hearing communities, there are culturally deaf communities where Deaf people have their own language and culture. Since they cannot hear sounds, their communication is not based on speech. A visual-gestural medium is used for communication which is called sign languages (SLs). Sign languages rely on using hand, facial expressions, body positions and further physical movements to convey meaning. However, spoken languages rely on sounds to express meaning. As viewed by Johnston and Schembri (2007, p.11) that SLs are natural languages of deaf signing communities.

\section{Sign Language: Language without Speech}

This section is about the concept of SL and some aspects related to SLs. To have a better understating about SLs, the section involves the following subsections dealing with some definitions by several scholars and linguists and the formational types of signs. Furthermore, some common misconceptions about SL are also mentioned.

\subsection{Definition of Sign Languages}

Sign languages have been defined by many scholars and linguists. Sutton-Spence (2005, p.1) defines sign languages as natural languages used by the Deaf people. In addition, sign languages are not series of gestures, but they are real languages which are independent of spoken languages. As viewed by Brown and Attardo (2005, p.282), sign language is a visual and gestural mode of communication having characteristics of natural languages. In the view of Trask, R.L. (1999, p.19), a sign language is a language whose medium of communication is signing. According to Pfau (2012, p. 513), sign languages are natural languages having complex grammatical structures which are the means of communication of Deaf people. Matthews (2007, p.367) claims that sign language is a system of human communication whose character is similar to spoken language, but different in modality.

In the view of what has been presented, it is clear that SL is a genuine human language primarily used by the deaf or hard of hearing people. It is a language that uses manual communication to express meanings. In addition, SL is independent of spoken language following its own path of development. Furthermore, SL is characterized by having the same properties as spoken languages such as duality of patterning and productivity.

\subsection{Who are Deaf People?}

Napier and Leeson (2016, pp.20-1) state that Deaf people are not those with a hearing loss who manage their capacity to hear through the use of a hearing aid and a cochlear implant (a small device which is put on the head). People with a hearing loss speak the spoken language 
depending on their devices. They are called hard of hearing who have a hearing loss either in childhood or early teens or as they age. Deaf people are those whose first language is a SL. They may be Deaf; they may wear hearing aids or have a cochlear implant; they may speak or make use of some hearing; but they prefer to communicate via SL.

Reagan (2010, p.4) refers Deaf and hearing impaired to different kinds of hearing loss:

a) a person who uses natural SL and integrates with the Deaf community,

b) a person who communicates through speech and integrates with the hearing community,

c) a person who does not know either a natural SL or the spoken language, but communicates through their homesigns and

d) a person who became Deaf due to aging (the elderly).

\subsection{Who are Deaf Sign Language Users?}

According to Napier (2016, p.13) and Napier and Leeson (2016, p.25), Deaf SL users belong to a linguistic and cultural minority. Every country has its own national SL and culture. Many countries have more than one SL. Deaf SL users belong to a transnational deaf community because they come from different countries. It is the visual-gestural nature of SLs that helps them find common basis for transnational communication. Such cross-linguistic communication is a pidgin based on iconicity and visual expression. For this reason, they can communicate across cultures to some extent. However, complex meaning cannot be conveyed through transnational signs.

\subsection{The Deaf Signing Community}

Tennant and Brown (1998, p.9) and Meir and Sandler (2008, p.8) mention that one of the characteristics of Deaf community is the use of a SL. They state that 'Deaf' with the capital ' $D$ ' refers to the Deaf people who are members of the Deaf community, while 'deaf' with a lowercase' $d$ ' refers to deaf people who are not involved in the Deaf community, i.e., the auditory condition. Deaf people shape the core of the Deaf community. They spend their time with other Deaf people. Most are employed in the hearing community and have hearing family members. As viewed by Johnston and Schembri (2007, p. 29) and Wilcox (2007, p.1113) that the Deaf community forms a distinct subculture. Sign language is used in the home, at social events and in schools. Furthermore, Deaf people value membership in which the majority of Deaf people marry other Deaf people. According to Mindess (2006, p.95) the Deaf community is like a family in which connectedness is highly valued, thus, Deaf people from various countries with different SLs can have conversation more quickly than hearing people of different spoken language depending on iconicity and visual-gestural expressions. 
It has become clear from the above three subsections that not only Deaf people are the users of SL but also hearing people such as those who are unable to physically speak or those who have troubles with the spoken language. Within the community, Deaf people form the linguistic and cultural minority group. Nowadays, there are many SLs in use: ASL, BSL, Australian Sign Language (Auslan), Langue des Signes Francaise-French Sign Language (LSF) etc...Both ASL and BSL are unrelated to each other.

\subsection{The Formational Types of Signs}

Signs are grouped into three formational types: manual signs, non-manual signs, and multi-channel signs (Johnston and Schembri, 2007, p.83).

\subsubsection{Manual Signs}

The majority of signs are manual made with the hands. There are one-handed and twohanded signs. A one-handed sign in Auslan WHITE is in Figure (1a). Two-handed signs are either symmetric or asymmetric depending on whether or not the handshapes are the same; Figure (1b) and (1c).

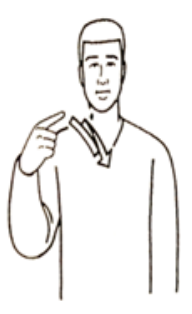

a. WHITE

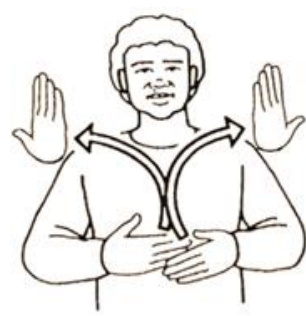

b. DAY

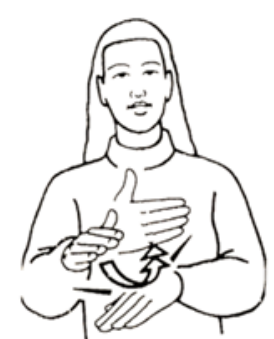

c. CAT

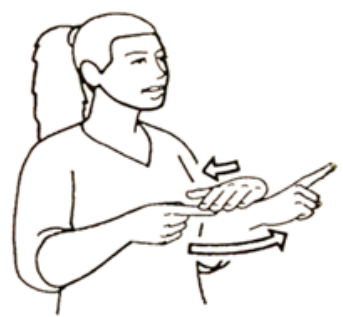

d. EXIT

Figure 1: Four signs in Auslan

Meir and Sandler (2008, p.27) and McGregor (2015, p.283) explain these types with examples: in the symmetric sign DAY, the hands move in mirror-image paths; and the second sign CAT, the dominant hand is active, while the subordinate hand remains fixed. In asymmetric signs one hand is dominant and the other is subordinate (Figure 1d).

\subsubsection{Non-manual Signs}

Bauer (2014, p.90) defines non-manual signs are produced by the upper part of the body other than the hands, such as the face, eyes, mouth and head. Liddell (2003, pp.12-3) says that the articulation of some signs does not only require the correct movement of the hands but also to configure the face and other body parts. This is exemplified by Johnston and Schembri (2007, pp. 96-7) for a non-manual sign in BSL and Auslan NO which is articulated by a headshake and the shoulder shrug meaning I DON'T KNOW. In question, the sign is accompanied by the raising of the eye-brows, widened eyes and a slight leaning forward of the head. Non-manual markers 
are originated either from the spoken languages as mouthings or they are grammaticalized gestures as facial expressions, e.g., eye gaze. Non-manuals are parts of the grammatical system (see Table 1).

Table 1: Non-manual signs

(Johnston and Schembri, 2007, p.97)

\begin{tabular}{|c|c|c|c|}
\hline Body & Action & Body & Action \\
\hline Head & $\begin{array}{l}\text { Shaking, Nodding, Turning left/right, Tilting } \\
\text { left/right/backwards/forwards, Moving backwards/ } \\
\text { forwards }\end{array}$ & Eye-brows & Raising, Lowering \\
\hline Mouth & $\begin{array}{l}\text { Opening, Closing, (Protruding, Rounding, Vibrating, } \\
\text { Pressing the lips together, Stretching) the lips, } \\
\text { Turning up / down the corners of the mouth, } \\
\text { Pushing the tongue down below the lower lip, Puffing out }\end{array}$ & Nose & $\begin{array}{l}\text { Hunching, Moving } \\
\text { forwards/ } \\
\text { backwards, } \\
\text { Turning left/ right } \\
\text { Wrinkling }\end{array}$ \\
\hline Eyes & $\begin{array}{l}\text { Closing/Opening, Blinking, Gazing forward /upwards, } \\
\text { Gazing to the left/right }\end{array}$ & Body & $\begin{array}{l}\text { Leaning forwards / } \\
\text { backwards/ sideways }\end{array}$ \\
\hline
\end{tabular}

It is clearly explained by Zeshan (2000, pp.42-4) and Bauer (2014, pp.90-4) that nonmanual markers differ from one SL to another, e.g., mouthings. Sandler and Lillo-Martin (2006, p.104) describe mouthings as full or partial voiceless articulation during the sign production similar to the spoken word. They co-occur with nouns and verbs. One of the functions of mouthing is to disambiguate two identical signs, i.e., perform a lexical role.

\subsubsection{Multi-channel Signs}

It is viewed by Zeshan $(2000$, p.110) that multi-channel signs are formed by a combination of manual and non-manual features. This is exemplified by Johnston and Schembri (2007, pp. 83-99) as the sign GULLIBLE produced by a manual gesture: hand moves upward and hold nose between the thumb and index finger; hold is released and this is accompanied by a non-manual gesture: a forward tilt of the head. Multi-channel signs co-occur with a set of non-manual gestures as facial expressions and movements of the head. The role of non-manual features in the expression of emotion is important. Should a signer look happy when signing HAPPY? Signers use a different facial expression while signing the question ARE YOU NOT HAPPY? This is because non-manuals are combined with manual signs to show grammatical functions such as questions.

From what has been presented, it becomes obvious that signs are produced by the simultaneous combinations of handshapes, locations, movements and orientations through the 
use of manual, nonmanual and multi-channel signs. Regarding the manual signs, the parameter of handedness is not contrastive in SLs, i.e., no sign is exclusively created by the right or left hand. The signer uses the dominant hand as the key articulator whether he/she right-handed or left-handed. For non-manuals are multifunctional used simultaneously with manual and nonmanuals. The above examples mentioned clarify that nonmanual signs play an important role in all level of grammar functioning as negation, interrogatives, sentence type, and etc...

\subsection{Myths and Misconceptions about Sign Language}

Liddell (2003, p.1), Johnston and Schembri (2007, p.12), Meir and Sandler (2008, p.2), and Emmorey (2002, pp.1-4) mention a number of misconceptions about SL. The common one is that sign is a grammarless communication via gestures. The following is the detail of the most common misconceptions:

\section{1) Is sign language universal?}

Sign language is not a universal language. Most SLs are mutually unintelligible. Various SLs exist and many of them have developed independently (Emmorey, 2002, pp.1-2). Sign languages are not similar in their vocabulary and grammar, e.g., Auslan uses a sign order where the actor precedes the verb and the undergoer, e.g., MAN KNOWS WOMAN. Argentinian Sign Language uses an actor-undergoer-verb sign order, e.g., MAN WOMAN KNOW. To signal negation a headshake is used in Auslan while signing WOMAN CAN DRIVE, The woman cannot drive, but in Greek Sign Language (GSL) a backward head tilt is used. A handshape used in Auslan is different from other SLs. Not only SLs vary from one community to another but variation exists in the vocabulary and grammar within specific SLs. Different signers may use different signs for a similar concept because of region, age, and education. Sign language differs from one part of the world to another; however, different SLs may have more points of similarities than the spoken languages (Johnston and Schembri, 2007, p.12).

Sign language is not universal. It is naturally developed by the members of the community who use them. Therefore, SLs are specific to that community and cannot be understood universally.

\section{2) Are sign languages based on spoken languages?}

Tennant and Brown (1998, p.9) and Sutton-Spence (2005, p.1) mention the belief that ASL, BSL or Auslan are English in signed form. Contrary to that belief, SLs are not derived from spoken languages. Sign languages are distinct languages that are not based on speech having its own grammar, sentence construction, idiomatic expressions, style, and regional variations. Johnston and Schembri (2007, p.13) add that many aspects of vocabulary and grammar are unrelated to English. Sign language and English are languages of a minority and majority. Borrowing from English is common because of the contact between the two languages. Many 
signs are based on fingerspelling of the first letter of the English words, e.g., D for DAUGHTER or fingerspelled in full, e.g., -S-O-N-. Thus, SLs are not based on spoken languages, but they may be affected by the language of the surrounding speaking community.

\section{3) Are sign languages pantomimes and gestures?}

Emmorey (2002, p.2) and Meir and Sandler (2008, p.32) state that the popular view that SLs are forms of pantomime or gestures is mistaken. It is believed that communication between signers is produced by pointing to objects, drawing pictures in the air or by acting out events. Sign languages are real languages and are not pantomime and gestures. Sutton-Spence and Woll (1999, p.9) claim that pantomimes are always iconic while signs can be arbitrary.

Özyürek (2012, p.626) defines gestures as meaningful movements of the body, the hands and the face which accompany the spoken and sign utterances. A sign is defined by Tennant and Brown (1998, p.9) as a gesture or hand movements modified by facial expressions to convey a concept.

Signs and gestures are similar in using parts of the body, but signs are used in place of speaking but gestures are used throughout speaking (Yule, 2014, p.201). Denham and Lobeck (2013, p.17) discuss that SLs differ from gestures: non-verbal gestures such as smiling. These bodily gestures express meaning; but they do not have structures as spoken or SLs. Gestures lack grammar: a handshake is an expression of greeting. All language users are capable of gesturing, while not all are capable of signing. Sutton-Spence and Woll $(1999$, p.168) state that signs can be combined to create sentences based on the grammatical rules while gestures cannot be combined into grammatical sentences (Green, 2014, pp.14-5).

Pantomime is imitating of activities describing objects and people without being physically present. A pantomime person may act out riding a bike using his/her own gestures and body movement. A pantomime is used to replace or complement speech. The sign SWIM resembles mimed representations of actions. The sentence I just got out of the car and I just (demonstration of turning around) is the sequential, complementary and pantomimic gesture (Johnston and Schembri, 2007, p. 24; Özyürek, 2012, p.629).

Therefore, it has been obvious that SLs are not pantomimes or gestures. Signs are used systematically while gestures are used randomly. The visual-gestural language of Deaf signers and the gestural communication of non-signers share some properties. Sign languages are rulegoverned and highly developed language having all the basic linguistic levels such as phonology, morphology, syntax, semantics, pragmatics etc... 


\section{4) Are sign languages always iconic?}

Johnston and Schembri (2007, p.15) mention the assumption that the meaning of signs comes from being pictures of what they represent. Signs have connections between their form and meaning, i.e., iconic. Iconicity is more common in SLs than in spoken languages. The greater degree of iconicity exists in vocabulary and grammar. Most signs in modern SLs are arbitrary: lack of a form-meaning relationship, e.g., YOUNG. In BSL, many signs are not totally arbitrary, but their meaning is iconic, e.g., the BSL sign MAN is related to beard and it means old in ASL. As Sutton-Spence and Woll (1999, p.170) exemplify COFFEE as iconic in ASL and BSL, but BSL focuses on drinking and ASL on grinding the beans. If all signs were completely nonarbitrary, all signs in all languages would be similar. Sign languages have signs that look the same but different in meanings, e.g., the BSL RABBIT is the same as the ASL HORSE.

Johnston and Schembri (2007, p.15) add that the formation of signs is not restricted to physically resemble their referents. The visual perception and manual production as well as language-specific formational pattern have influences. Changes in signs make some iconic signs develop into arbitrary signs. When signs are originally iconic; the form-meaning relationship may be specific to that language. The sign WOMAN, in Auslan, is signed with a B hand moving down the cheek which indicates the smooth cheeks of a woman face (Figure 2). In Israeli Sign Language (ISL), the index and thumb pinch the earlobe (see iconicity).

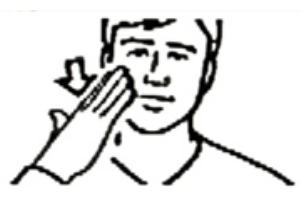

Auslan

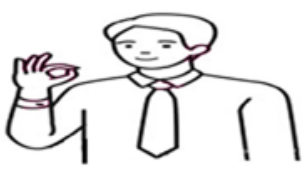

ISL

Figure 2: Sign for WOMAN for two unrelated sign languages

\section{5) Do sign languages have similar expressive capacity as spoken languages?}

It is stated by Emmorey (2002, p.3) and Johnston and Schembri (2007, p.17) that SLs have the same capacity for expressing complex meanings as spoken languages: complex concepts, e.g., CULTURE and LINGUISTICS. Any word can be interpreted by means of fingerspelling. The sign vocabulary is smaller than other spoken languages, but the expressive capacity of SLs is not limited.

\section{6) Are sign and spoken languages processed by the brain in similar ways?}

According to Johnston and Schembri (2007, pp.17-8), SLs are produced by the hands and body and perceived through vision. Spoken languages are produced by the speech organs and perceived by hearing. This does not make a difference to sign and spoken language processing. 
The linguistic functions are controlled by the left hemisphere while visual-gestural skills are controlled by the right hemisphere. The damage of the right hemisphere may lead to the loss the ability of drawing. The damage of the left hemisphere may result in linguistic problems as aphasia: the inability to produce grammatical sentences. Deaf signers with left hemisphere damage had difficulties with grammatical skills but had the ability to draw. Signers with right hemisphere damage had difficulties of visual-gestural skills but used grammatical skills. The left hemisphere is for the comprehension and production in SLs. The right hemisphere is used in face-to-face communication whether sign or spoken.

It is evident that the difference in modality does not make any difference in language processing between SLs and spoken languages. Deaf signers with the left hemisphere damage show aphasia as hearing people. When left hemisphere regions are damaged, both signers and speakers have language disturbances. There are many similarities in the processing of both languages which show the uniformity in the neural systems.

\section{7) Do children learn spoken and sign languages in similar ways?}

Jantunen and Takkinen (2010, p.319) maintains that children acquire SLs in the same way as spoken languages. For Deaf children with signing parents, SL acquisition starts at birth. From the age of six months, they begin to babble on their hands and imitate the SL they see around them. The production of their first sign is at their first birthday. No difference is found in the timing of the first sign and the first word (Johnston and Schembri, 2007, p.18).

The one-sign stage, like the one-word stage, continues as the Deaf children add new signs to their vocabulary (Lillo-Martin and Pischler, 2006, p.244). Johnston and Schembri (2007, pp.18-9) explain that the production of sign FATHER by signing children is the same as speaking children learning spoken languages. Deaf children make errors in production with incorrect handshapes or movements, e.g., slip of the hand in the same way speaking children are unable to pronounce the sounds. When they are two years of age, children begin to use their signs in twosign combinations as WANT MILK. By two and a half, there is a growing of vocabulary and sentences become much longer. A few years they master all aspects of the language. Hearing children from Deaf families learning both sign and spoken languages pass through similar stages.

Thus, it is obvious that in SL acquisition Deaf children pass through similar processes at the same age as hearing children learning spoken languages. If the child interacts with BSL, for example, then he will learn BSL. Generally, in language acquisition the language is easier to be learned when it is used by the surroundings and when the child has enough exposure. However, it is more difficult when there are obstacles. 


\section{8) Were sign languages invented by hearing people?}

Marscharck et al. (2006, p.6) and Johnston and Schembri (2007, pp.19-20) mention that no individual, hearing or Deaf, invented SLs. Sign languages have been used among Deaf people before the establishment of schools for the Deaf. In the writings of Plato, there are some references for the use of SL by Deaf people. In Paris, Abbé de I'Epée is the first one who learned LSF from Deaf people and used these signs as the medium of instruction. Schick (2006, pp.1236) points out that Deaf people used homesigns: a limited vocabulary of signs or gesture system created by the Deaf to communicate with hearing parents. These homesigns began to develop by sharing them among Deaf people, e.g., Nicaragua Sign Language (NSL). Johnston and Schembri (2007, pp.19-20) discuss that this myth comes from two reasons:

First, the creation of artificial sign systems by hearing people such as Manual Sign Codes (MSCs): methods for Deaf children to have access to spoken language and to represent a spoken language in a gestural-visual modality. These artificial SLs facilitate learning of a spoken language to Deaf children who have no auditory input from the spoken language and provide linguistic and communicative input in a different modality. The signs in MSCs are taken from natural SLs (Reagan, 2010, p.6). Emmorey (2007, p.710) mentions a number of English-based sign systems: Signed English (SE), and Manually Coded English (MCE). In artificial languages words and grammatical elements are replaced by a sign. The syntax of these manual codes is the same as those of English (Fromkin et al., 2003, pp. 21-2), e.g., Signed Exact English (SEE) is a sign system designed to visually represent English syntax and lexicon. Second, the fingerspelling systems used by the Deaf were used by hearing people. The two-handed manual alphabet used in BSL and Auslan has its origins in fingerspelling used by hearing people. American Sign Language uses the one-handed manual alphabet (see Figure 3) (Tennant and Brown, 1998, pp. 26-8; Rambhau, 2013, pp.1-2). 


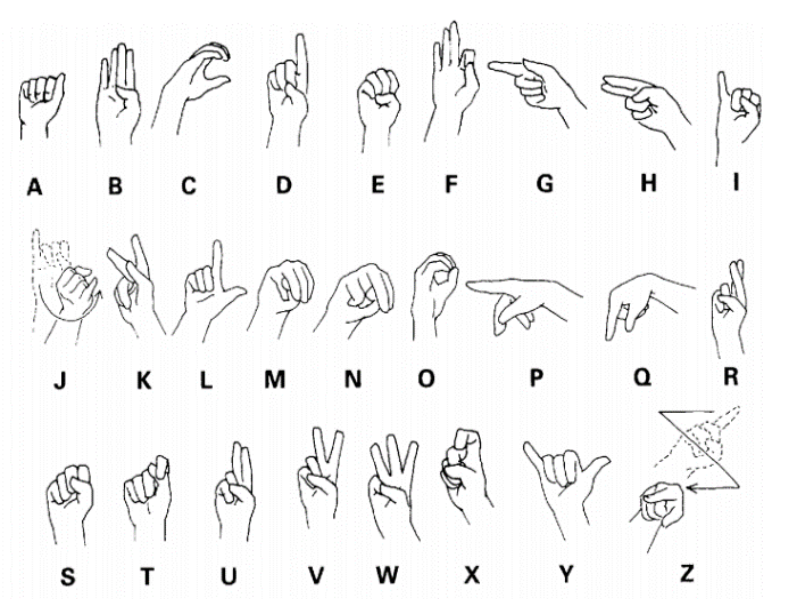

a) ASL one-handed manual alphabet
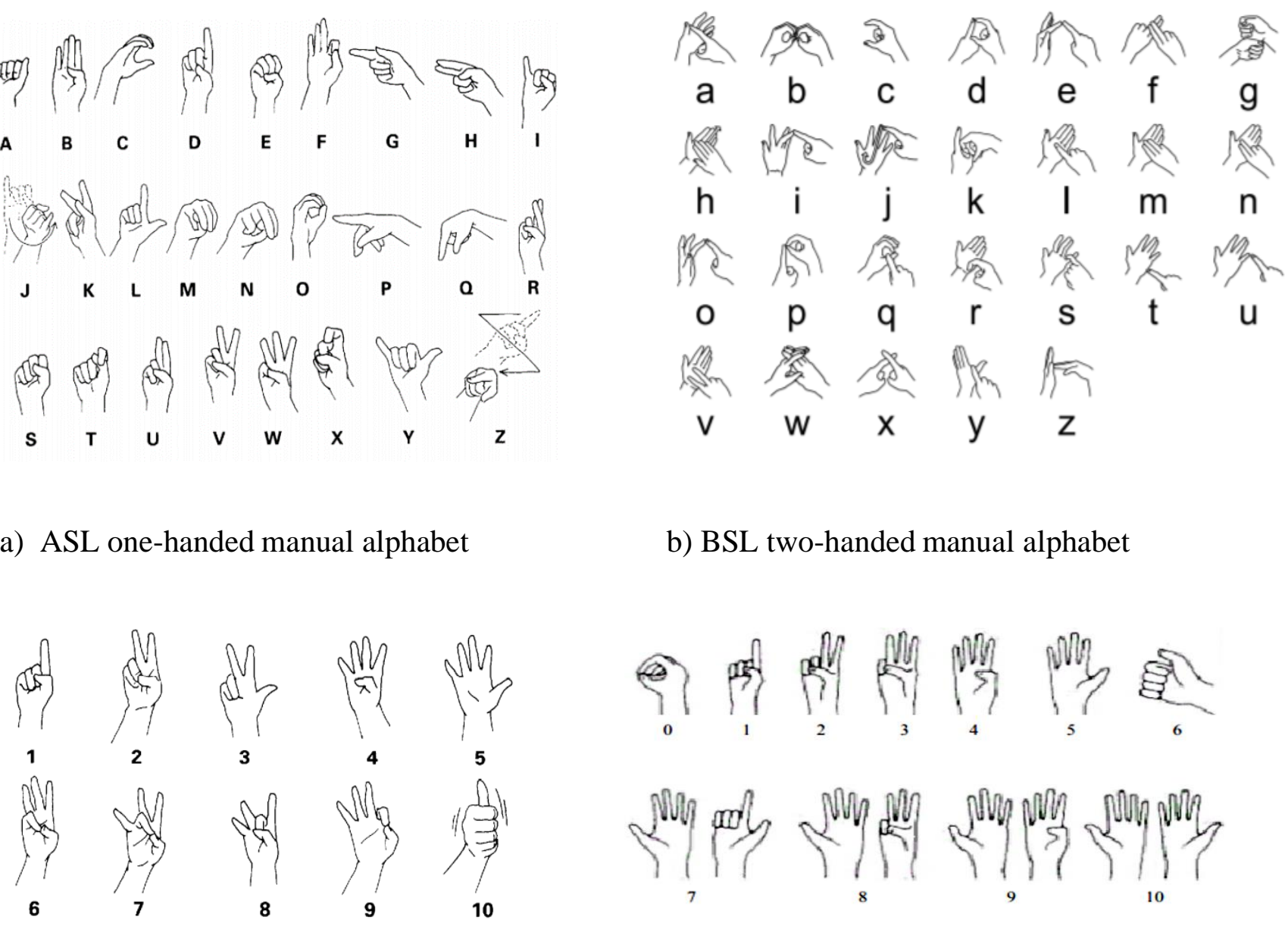

c) ASL numbers

b) BSL two-handed manual alphabet

Figure 3: ASL and BSL manual alphabets and numbers

It can be said that SLs were not invented by the hearing people. Sign languages evolved naturally in Deaf communities when Deaf people began to live together. Wherever communities of Deaf people exist, SLs have developed.

\section{9) Can sign languages be written down?}

Sutton-Spence (2005, p.2) say that people believe that SLs cannot be real languages because of the lack of a written form. Sign languages make use of facial expressions which is difficult to have a writing system. In spoken language much has also been omitted form the written form such as accent. Johnston and Schembri (2007, p.21) mention two forms of writing systems forms: glossing and notation. Glossing is the method of describing signs. Glossing a sign is writing its meaning using the spoken translations of signs. The meaning is written in lowercase capital letters CAT (Sutton-Spence and Woll, 1999, p. xi). Notation is the use of symbols to represent the physical features of the SL. The methods are Stokoe Notation System developed by Stokoe and Hamburg Notation System (HamNoSys): the institute for German Sign Language-Deutsche Gebärdensprache (DGS) in Hamburg (Takkinen, 2008, p.87). 
It is quite clear that SLs can be written down. In notating signs HamNoSys is an accurate system depending on some parameters such as non-manual features, handshape, orientation, location and movement (type, manner and repetition). For example, HamNoSys symbols for handshape: $\square$ indexfinger extended, for location: head height,

for orientation:

right, up

$\nabla \sim$ a body $\square$ shoulder (see more Takkinen, 2008, pp.90-2).

\subsection{Sign Language and its Relationship with Spoken Language}

As stated by Sutton-Spence and Woll (1999, pp.10-12) and Denham and Lobeck (2013, p.16) that SLs share characteristics with spoken languages. They use the same units of spoken languages. There are differences between SLs and spoken language related to modality. Sign languages show all the design features of spoken languages. Some signs are non-arbitrary: the $1^{\text {st }}$ person singular pronoun $I$ is represented by pointing at oneself, but most signs are arbitrary. In ASL, EAT is iconic, but the sign for MISTAKE is arbitrary. Thus, SLs have similar features of arbitrariness as spoken languages. Sign languages are linguistic systems having syntax, morphology, phonology, and etc... They have creativity, productivity and duality of patterning. For duality: each sign is made up of a handshape, a series of movements, and a location. Each alone is meaningless, but when they are put together a sign is formed, e.g., in BSL, FLOWER has a handshape, a location at the nose, and a movement from one side of the nose to the other. In BSL, there are a small number of handshapes which can be used at various locations and movements to form different signs. Signs also have displacement: Deaf signers can communicate about events in the past, present and future and about imaginary and real world. Sign languages have dialects and they change overtime.

Sutton-Spence (2005, p.4) adds that spoken languages are produced by the vocal tract and perceived by the auditory channel while SLs are produced by the hands and non-manual articulators are perceived visually. Perniss et al. (2007, p.1) confirm that modality plays a significant role in forming the structure. The visual-gestural modality provides the possibility of simultaneity. Spoken language production is sequential: one sound follows another. In the visual medium, multiple components can be produced at the same time.

\subsection{Iconicity}

Zeshan (2000, p.50) defines iconicity as the non-arbitrary correspondence between the sign and its referent. Taub (2004, p.19) and Sandler and Lillo-Martin (2006, p. 493) state that iconicity is the relation between form and meaning. It is present in SLs in all linguistic levels. The form for the concept BOOK is the two flat hands with the palms facing upwards and touching each other. As languages change, signs become less iconic. Brentari (2012, pp.38-9) illustrates with examples that iconicity is language-specific: the sign TREE differs in Danish Sign language (DSL) and ASL, but all are iconic. Iconicity is one of the factors why deaf signers from different 
families can communicate despite differences in lexicon and grammar. Iconicity and arbitrariness build expressions using handshape, orientation and movement.

\subsubsection{Cultural/Conceptual Definition of Iconicity}

Taub (2012, pp.390-2) gives more details on iconicity which takes culture and conceptualization into account. In their view iconicity is a relationship between the human's mental image and referents. These mental images are from experiences common to all humans and by experiences specific to certain cultures. To know the meanings of signs in Lingua dei Segni Italiana: Italian Sign Language (LIS), some meanings were guessed by non-Italian nonsigners. Some were common to non-Italian deaf signers; and others were easier for Italian nonsigners. Some related to the experience of deafness and signing, and some have a basis in Italian culture. The notion of form-meaning resemblance is based on the human's ability to create a conceptual resemblance.

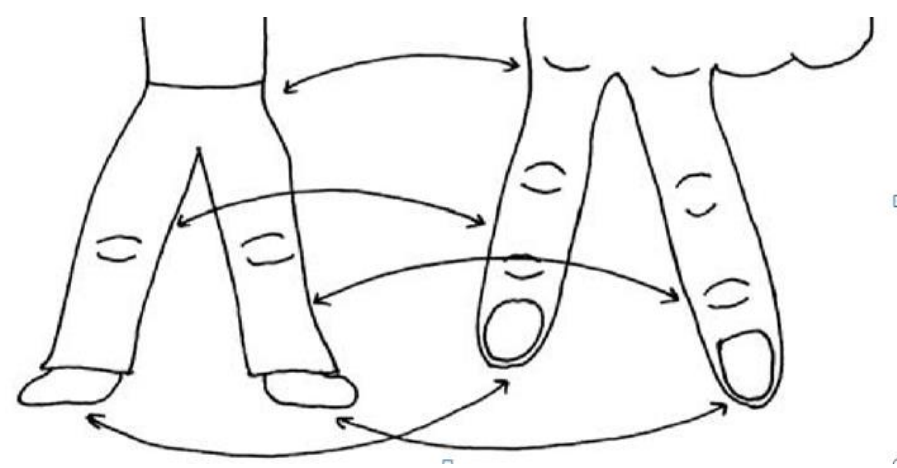

Figure 4: Correspondences between human legs and index and middle finger

Taub (2012, p.390) further adds that in linguistic iconicity a resemblance exists between the phonetic form (sound, handshape) and the mental image. Figure 4 is the images of human legs and the forefinger and middle finger extended from a fist.

\subsubsection{Iconic Gestures and Iconic Signs}

According to Taub (2012, p.393-6), gestures accompanying speech differ from gestures occurring alone carrying the whole message: thumbs-up. Some are created during communication, e.g., the woman is telling a story about a person peeling a banana. While saying those words, her left-hand shapes as if she were holding the banana, and she moves her right hand downward three times as if she were peeling the banana (Figure 5): 

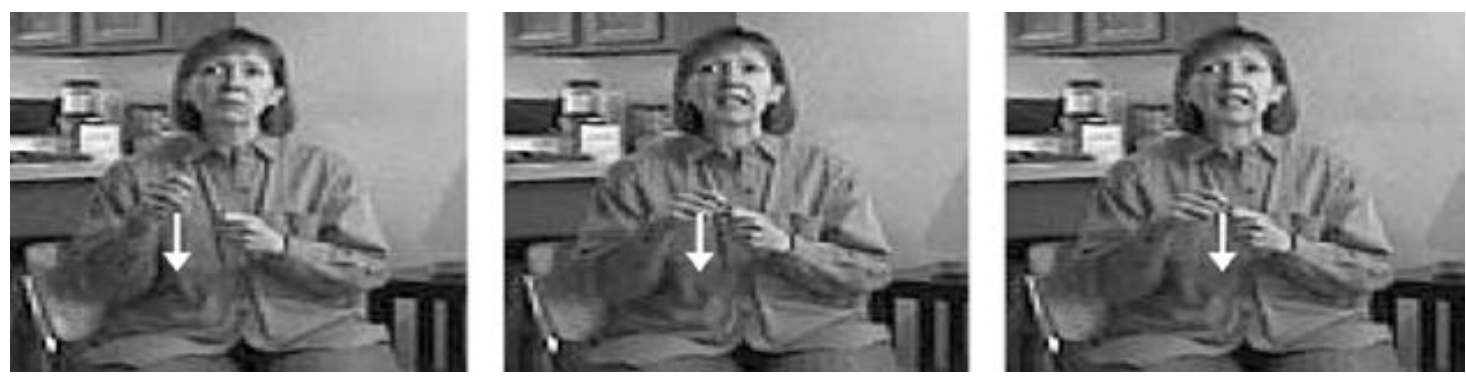

Figure 5: Iconic gesture accompanying peels of the banana

Figure 6 shows an iconic sign of BANANA: the dominant closed $X$ handshape moves down the upright non-dominant handshape twice and shifts the orientation between both movements. The sign shows a concept: banana, a type of fruit not an action. Iconic gestures and iconic signs are the same in having the correspondence between form and referent. The difference is through the intention: the gesturer's intent is illustrative (to show an image), and the signer's intent is non-illustrative (to refer to a concept).
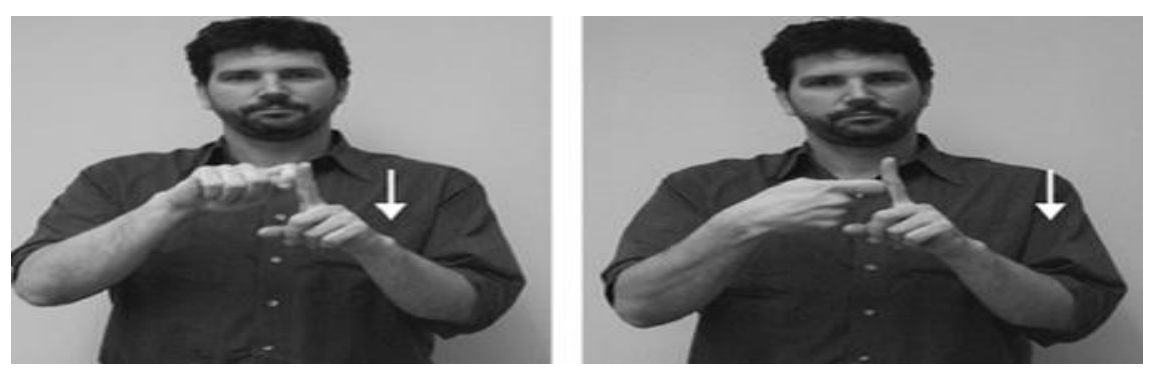

Figure 6: The ASL sign BANANA

\subsubsection{Sign Languages are more Iconic than Spoken Languages}

Taub (2004, p.9; 2012, pp.404-5) confirms that SLs have more iconic items than spoken languages, i.e., it is greater in sign modality because there are more visual and gestural images than auditory images, e.g., there is no sound for TABLE; but there is a shape. Taub (2004, pp.29-30) adds that there are different iconic signs of a single image, e.g., the signs meaning tree in ASL and DSL are iconic but different in form: in ASL TREE, the position of the hands and forearms resemble a tree and the Danish uses the hands tracing a tree's branches and trunk. The form of TREE resembles the prototypical tree: the horizontal non-dominant forearm, the ground; the vertical dominant forearm, the trunk, and the spread fingers of the dominant hand are the branches. The shapes of the articulators represent the shapes of the referent called shape-for-shape iconicity (Figure 7). Emmorey (2002, p.17) exemplifies the spoken iconicity: the onomatopoeic word ding, the sound of a bell. 


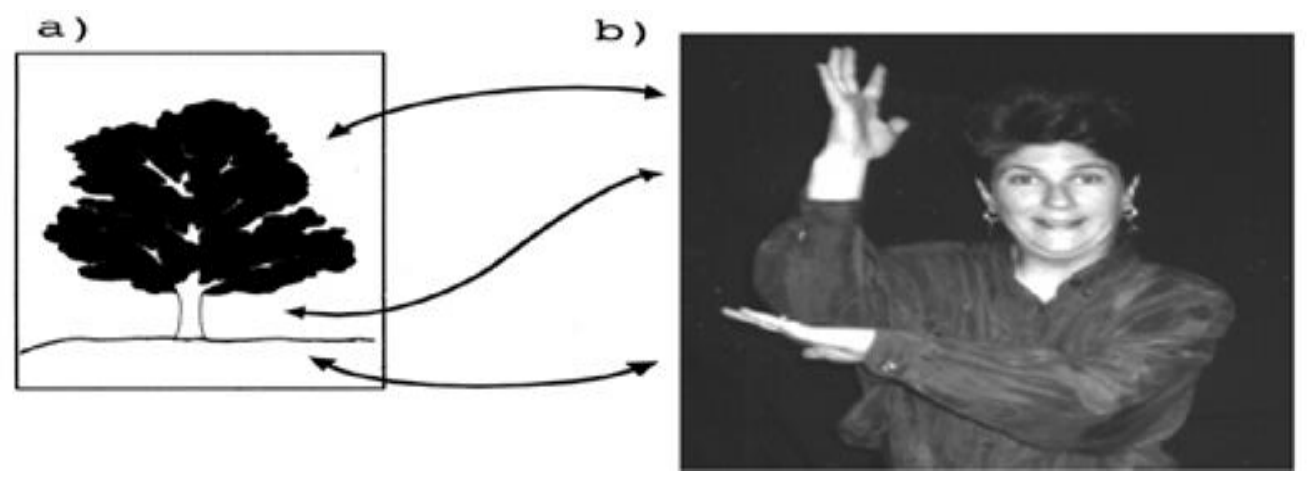

Figure 7: The correspondence between (a) a prototypical image of a tree and

(b) American Sign Language TREE.

What can be concluded from the above subsections about iconicity is that iconicity is a crucial factor in sign creation. Iconicity is an important criterion regarding relationships among SLs because the similarity of signs is based on iconicity. It has been clear that iconicity is language-specific and culture-specific. The use of iconicity explains the reasons why Deaf signers from different families interact despite the cross-linguistic variations in lexicon and grammar.

\subsection{The Acquisition of Sign Language}

This section is about the acquisition of SL by children and adults. It includes the following subsections which primarily deal with natural SL acquisition by native and non-native Deaf children. These subsections explore how children develop their first SL and how late learners learn SLs. Furthermore, they focus on similarities in acquisition between SLs and spoken languages regardless of differences in modality.

\subsubsection{Acquiring a Sign Language as a First Language}

According to Anderson (2006, p.137) and Baker et al. (2008, p.9) the majority of Deaf children are born into hearing and non-signing parents. These children may acquire SL haphazardly. Napier and Leeson (2016, pp.87-9) mention that most of the Deaf children have cochlear implants and many of them receive limited access to a SL during the critical period. Very few Deaf children are brought up into families where a SL is their mother tongue and few of them have early exposure to a SL. Children with an early hearing loss are users of SL. Deaf children develop their acquisition of SL from homesign. They must have contact with other Deaf children to develop grammatical use. Both pass through the two-word stage at around 18 months of age and complete at five. The left hemisphere is dominant as in spoken language, and Broca's and Wernicke's aphasias are from the same brain regions of Deaf signers. Most adult SL users do not acquire the language as a native language. The acquisition of post critical period leads to a different form by native signers. Hearing children from Deaf parents are bilingual using the SL of their parents and the spoken language of the community. 
As viewed by Bogaerde and Baker (2008, pp.141-5) that language mixing occurs in families with both hearing and Deaf members because of the bilingual or mixed input.

Meir and Sandler (2008, p.2) and Napier and Leeson (2016, pp.87-9) point out that the stages of SL acquisition in Deaf children paralleled those in hearing children. Hearing children need experience while interacting with adults. This is true with Deaf children learning SLs. When Deaf children have conversations with adults, they realize the rules and use them. But if they are exposed to incomplete language models, their language will be a mixture of forms: a mix of English, SL and gestures. The language children acquire depends on the linguistic group. All languages are learnable when there is exposure. Deaf babies use gestures although their parents do not sign to them. They have a natural motivation for communication. Language is learned from the language users, e.g., BSL is learned from users of BSL (SuttonSpence and Woll, 1999, p.12) (see also Volterra et al., 2006, pp.58-61).

\subsubsection{Who is a Native Signer?}

Tennant and Brown (1998, p.9) and Baker et al. (2008, pp.5-6) claim that children acquire a SL from birth from deaf parents are native signers. A native signer is someone who has Deaf parents and their acquisition of SL begins prior to age three. People with hearing loss as infants before they speak are native signers if they have SL input. As Emmorey (2002, p.205) and Napier and Leeson (2016, pp.91-2) state that the age of three to five is the critical period of SL acquisition. When growing up in a deaf family, the transmission of SL for native signers is easier from parent to child. Children acquire a SL as their mother tongue. Deaf parents who are SL users support language learning during the critical period of SL acquisition. There are hearing native signers who are users of SLs. They are native SL users grown up using SL with deaf parents. They acquire SL as a first language. Their enculturation crosses the cultures of both the hearing and deaf world.

Napier and Leeson (2016, pp.93-4) add that hearing Children of Deaf Adults (Codas) acquire a SL as first language. They code-blend between a spoken and SL: using different modalities and articulators. If the primary language is a SL, a hearing child learn the spoken from other sources.

\subsubsection{Non-native Deaf Signers}

Napier and Leeson (2016, p.94) confirm that a SL is acquired as a non-native language for the Deaf children and adults. Some Deaf adults learn a SL and have full mastery of the spoken language in childhood. This is because the acquisition of a first language is delayed for many Deaf children. Sign language learning is L1 learning that starts at a late age. Such delayed learning occurs in late childhood and adulthood because Deaf children have no access to SL input and some receive cochlear implants. Late learners acquire bilingual capacity. As 
the age of L1 acquisition increases, the capacity of late learners to understand SLs decreases. For those Deaf people involved with the signing community, language use is one of the markers to identity shifting between an insider and an outsider.

The data in the above three sections provide evidence of the similarities between spoken and SLs in the stages of SL acquisition. It has been demonstrated that SLs of Deaf communities support the concept that human beings are born with the ability to acquire languages. For Deaf children the acquisition of a SL follows similar developmental processes as hearing children if they are exposed to SL input from the early ages. This is a proof for the human linguistic ability and an evidence of the universality of language. It is clear that no individual is programmed to acquire a specific language and that language acquisition and use are not dependent on the human's ability to produce and hear sounds, but on an abstract cognitive ability which is biologically determined.

\section{Conclusions}

The current paper has shown how the study of SL is crucial in understanding the shared and the varied aspects of human language. Through the study of SL linguistics many questions can be explored about human language such as communication modality, iconicity and the relationship of language with the linguistic gestural system such as signs.

It has become quite clear that SLs are not universal. Sign languages vary from one community to another. Similarly, SLs are not dependent on the spoken language. Sign languages are fully dynamic true languages that are not based on speech having its own grammar, sentence construction, style, and regional variations. In addition, SLs are neither pantomimes nor gestures. Gestures lack grammar, but signs have structures like the spoken language. It has also been concluded that signs are not always iconic; signs are often arbitrary that do not necessarily have a visual relation to the referent. More importantly SLs are not invented by the hearing people. On the contrary SLs evolved within the deaf signing community. A misconception that SLs cannot be written down is mistaken. Sign languages have their systems of writing.

Furthermore, Deaf children acquiring SL as their L1 pass through development stages similar to children learning spoken languages if they have SL exposure. Sign languages resemble spoken languages in all major aspects. In SL processing, as in spoken language production, the left hemisphere is active and aphasia refers to the same brain area in Deaf signers as well as hearing speakers. There are similar patterns in comprehension and production of sign and speech. 


\section{جهمكه ناجاومكان دمربارمى زمانى نامازئ}

\section{خوناو سليّمان يِيروّت}

بهاشى زمانى ئينكيزى ، كوليزى زمان، زانكوى صلاح الدين، هلوليّر، هلهيمى كوردستان، عيّراق.

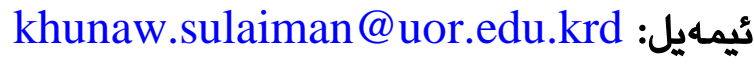

\section{ووريا عزاللين على}

بهاشى زمانى ئينكليزى ، كوليزّى زمان، زانكوى صلاح الدين، هلهوليّر، هلهيّمى كوردستان، عيّراق. ئيمهيل: wryaizzadin@yahoo.com

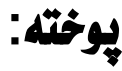

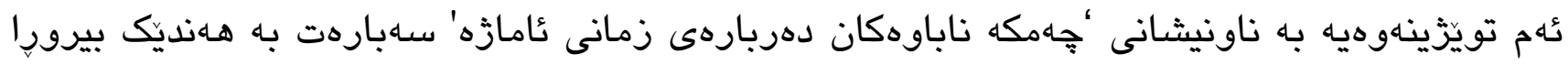

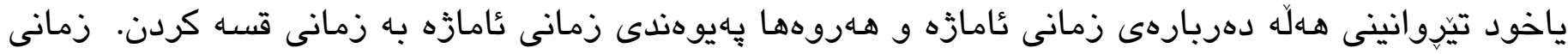

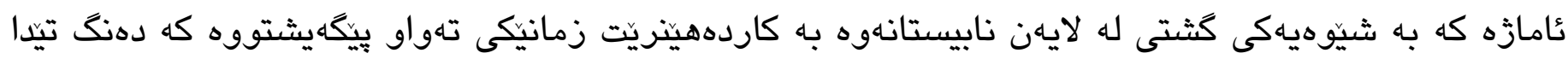

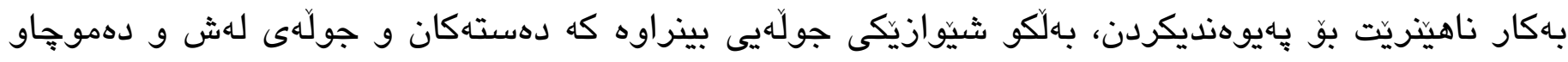

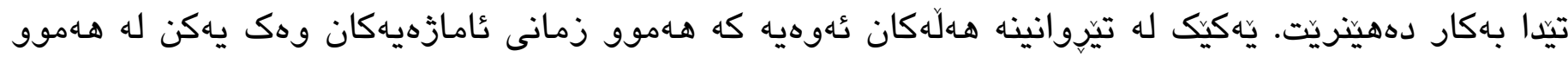

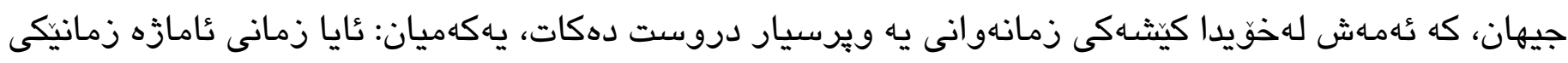

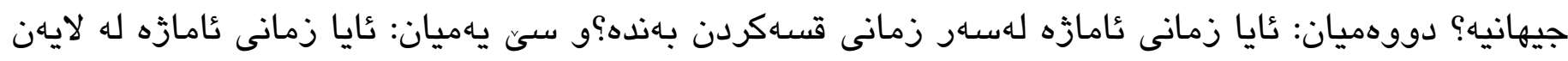

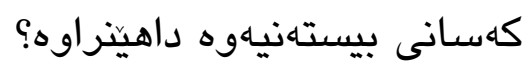

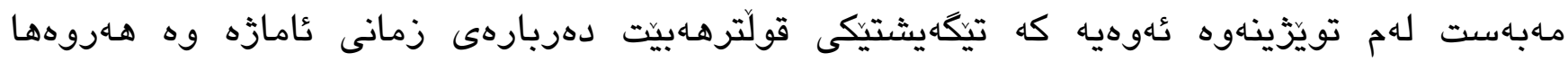
دياريكردنى خاله لهيه

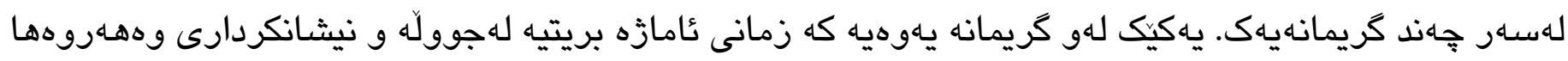

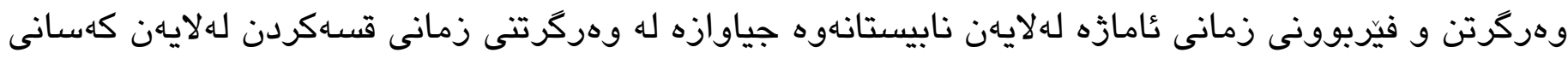
•بس

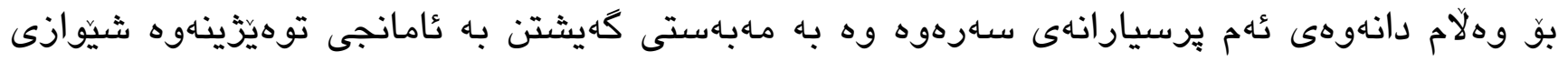

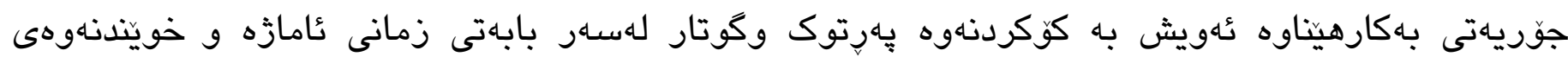


سـارجاوهكان دواتر شيكردنهوهى زانيارياكان. يهكيك له ئهنجامـكان ئهوهيه كه زمانى ئامازه زمانيكى جيهانيه

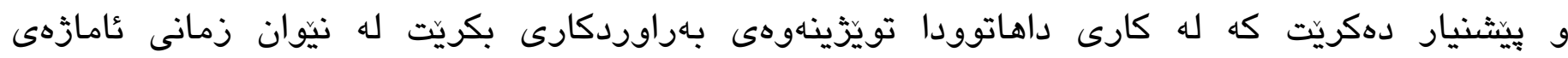

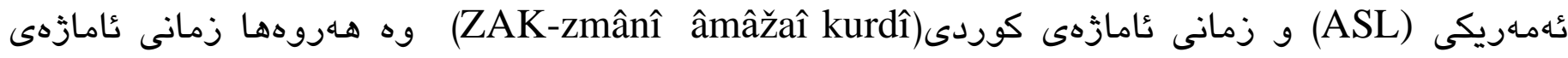
بهريتانى (BSL) و زمانى ئامازهى كوردى ZAK لهسهر ئاستى هـهوو بابهته زمانهوانيهكان. كليله ووشهكان: زمانى ئامازه، شيّوازى جوولّهيى بينراو، نابيستان، جوّرهكى. 


\section{References}

Anderson, Diane (2006). "Lexical Development of Deaf Children Acquiring Signed Languages". In Advances in the Sign Language Development of DeafChildren edited by Schick, Brenda; Marschark, Marc, and Spencer, Patricia Elizabeth. Oxford: Oxford University Press, pp.134-160.

Baker, Anne; Bogaerde, Beppie van den, and Woll, Bencie (2008). "Methods and procedures in sign language acquisition studies". In Sign Language Acquisition edited by Baker, Anne and Woll, Bencie. Amsterdam: John Benjamins B.V., pp.1- 49.

Bauer, Anastasis (2014). The Use of Signing Space in a Shared sign Language of Australia: Sign Language Typology. Berlin: Mouton De Gruyter and Ishara Press.

Bogaerde, Beppie van den and Baker, Anne (2008). "Code mixing in mother-child interaction in deaf families". In Sign Language Acquisition edited by Baker, Anne and Woll, Bencie. Amsterdam: John Benjamins B.V., pp.141-163.

Brentari, Diane (2012). 'Phonology'. In Sign Language: An international Handbook edited by Pfau, Roland; Steinbach, Markus and Woll, Bencie. Berlin: De Gruyter Mouton, pp.21-55.

Brown, Steven and Attardo, Salvatore (2005). Understanding Language Structure, interaction, and Variation: An Introduction to Applied Linguistics and Sociolinguistics for Nonspecialists. Michigan: University of Michigan Press.

Denham, Kristin and Lobeck, Anne (2013). Linguistics for Everyone: An Introduction. $2^{\text {nd }}$ ed. New York: Wadsworth, Cengage Learning.

Emmorey, Karin (2002). Language, Cognition, and the Brain: Insights from Sign Language Research. London: Lawrence Erlbaum Associates, Inc.

Emmorey, Karen (2007). "The Psycholinguistics of Signed and Spoken Languages: How Biology Affects Processing". In the Oxford Handbook of Psycholinguistics edited by Gaskell, M. Gareth. Oxford: Oxford University Press, pp. 202-721.

Fromkin,Victoria; Rodman, Robert, and Hyms, Nina (2003). An Introduction to Language. Boston: Heinle Thomson.

Green, Jennifer (2014). Drawn from the Ground: sound, Sign and Inscription in Central Australian Sand Stories. Cambridge: Cambridge University Press.

Jantunen, Tommi and Takkinen, Ritva (2010), "Syllable Structure in Sign Language Phonology". In Sign Languages edited by Brentari, Diane. Cambridge: Cambridge University Press.

Johnston, Trevor and Schembri, Adam (2007). Australian Sign Language: An introduction to Sign Language Linguistics. Cambridge: Cambridge University Press.

Liddell, Scott, K. (2003). Grammar, Gesture and Meaning in American Sign Language. Cambridge: Cambridge University Press. 
Lillo-Martin, Diane and Pishler, Deborah Chen (2006). "Acquisition of syntax in Signed Languages". In Advances in the Sign Language Development of Deaf Children edited by Schick, Brenda; Marschark, Marc, and Spencer, Patricia Elizabeth. Oxford: Oxford University Press, pp. 231-261.

Marschark, Marc; Schick, Brenda, and Spencer, Patricia Elizabeth (2006). "Understanding Sign Language Development of Deaf Children". In Advances in the Sign Language Development of Deaf Children edited by Schick, Brenda; Marschark, Marc, and Spencer, Patricia Elizabeth. Oxford: Oxford University Press, pp. 319.

Matthews, P. H. (2007). Oxford Concise Dictionary of Linguistics. $2^{\text {nd }}$ ed. New York: Oxford University Press. McGregor, William B. (2015). Linguistics: An Introduction. $2^{\text {nd }}$ ed. London: Bloomsbury Academic.

Meir, Irit and Sandler, Wendy (2008). A Language in Space: The Story of Israeli Sign Language. London: Lawrence Erlbaum Associates, Traylor and Francis Group.

Mindess, Anna (2006). Reading between Lines: Intercultural Communication for Sign Language Interpreters. $2^{\text {nd }}$ ed. Boston: Intercultural Press.

Napier, Jemina and Leeson, Lorraine (2016). Sign Language in Action. Hampshire: Palgrave Macmillan.

Napier, Jemina (2016). Linguistic Coping Strategies in Sign Language Interpreting. Washington, DC: Gallaudet University Press.

Özyürek, Asli (2012). “Gesture”. In Sign Language: An international Handbook edited by Pfau, Roland; Steinbach, Markus and Woll, Bencie. Berlin: De Gruyter Mouton, pp. 626-646.

Perniss, Pamela; Pfau, Roland and Steinbach (2007). "Can't You See the Difference? Sources of Variation in Sign Language Structure”. In Visible Variation: Comparative Studies on Sign Linguistics Structure edited by Perniss, Pamela; Pfau, Roland and Steinbach. Berlin: Mouton De Gruyter, pp.1-34.

Pfau, Roland (2012). 'Manual Communication Systems: evolution and variation'. In Sign Language: An international Handbook edited by Pfau, Roland; Steinbach, Markus and Woll, Bencie. Berlin: De Gruyter Mouton, pp.513-551.

Rambhau, Pingale Prerna (2013). "Recognition of Two Hand Gestures of Word in British Sign Language”. In International Journal of Scientific and Research Publications, Volume 3, Issue 10, October 2013, pp.1-5.

Reagan, Timothy (2010). Language Policy and Planning for Sign Languages. Washington, DC: Gallaudet University Press.

Sandler, Wendy and Lillo-Martin, Diane (2006). Sign Language and Linguistic Universals. Cambridge: Cambridge University Press.

Schick, Brenda (2006). “Acquiring a Visually Motivated Language: Evidence from Diverse Learners". In Advances in the Sign Language Development of Deaf Children edited by Schick, Brenda; Marschark, Marc, and Spencer, Patricia Elizabeth. Oxford: Oxford University Press, pp. 102-134.

Sutton-Spence, Rachel and Bencie, Woll (1999). The Linguistics of British Sign Language: An Introduction. Cambridge: Cambridge University Press. 
Sutton- Spence, Rachel (2005). Analyzing Sign Language. London: Palgrave Macmillan.

Taub, Sarah, F. (2004). Language from the Body: Iconicity and Metaphor in American Sign Language. Cambridge: Cambridge University Press.

Taub, Sarah, F. (2012). "Iconcity and Metaphor". In Sign Language: An international Handbook edited by Pfau, Roland; Steinbach, Markus and Woll, Bencie. Berlin: De Gruyter Mouton, pp.388-411.

Tennant, Richard, A. and Brown, Marianne Gluszak (1998). The American Sign Language Handshape Dictionary. Washington, DC: Gallaudet University Press.

Takkinen, Ritva (2008). "Some observations on the use of HamNoSys (Hamburg Notation System for Sign Languages) in the context of the phonetic transcription of children's signing". In Sign Language Acquisition edited by Baker, Anne and Woll, Bencie. Amsterdam: John Benjamins B.V., pp. 87-105.

Trask, R.L. (1999). Language: The Basics. $2^{\text {nd }}$ ed. London: Routledge.

Volterra, Virginia; Iverson, Jana M., and Castrataro, Marianna (2006). "The Development of Gesture in Hearing and Deaf Children". In Advances in the Sign Language Development of Deaf Children edited by Schick, Brenda; Marschark, Marc, and Spencer, Patricia Elizabeth. Oxford: Oxford University Press, pp. 4670.

Wilcox, Sherman (2007). "Signed Languages". In The Oxford Handbook of Cognitive Linguistics edited by Geeraerts, Dirk and Cuyckens, Hubert. New York: Oxford University Press, pp.1113-1136.

Yule, Gorge (2014). The Study of Language. $5^{\text {th }}$ ed. Oxford: Oxford University Press.

Zeshan, Ulrike (2000). Sign Language in Indo-Pakistan: A Description of a Signed Language. Amsterdam: John Benjamins B.V. 